\title{
Seismic study on skin effect of bamboo-bonded wood structure
} LIU Dewen ${ }^{1, \text { a }}$, GUO Zhongli ${ }^{2, b}$, DAI Bihuil ${ }^{1}$, HAN Li ${ }^{1}, X$ IA Binghua ${ }^{1}$, QI Rongqing ${ }^{1}$, LUO Xiaoya ${ }^{1}$, LI Jing $^{1}$, HAN Yu ${ }^{1}$, WANG Chenxing ${ }^{1}$, JIANG Shujiang ${ }^{1}$, XIONG Zanlin $^{1}$

${ }^{1}$ Southwest Forestry University, Yunnan Provincial Key Laboratory of Wood Adhesives and Glued Products, Kunming , P. R. China

${ }^{2}$ Anning teacher training schools, Kunming , P. R. China

aemail:350376315@qq.com

bemail:2625622369@qq.com

\section{Keywords: Wooden architecture, Skin effect, Opening rate, Lateral resistance}

Abstract: In the construction industry, according to the study on the skin effect of some scholars, showing the skin effect of the wooden structure not only has important significance in strengthening the structural strength and reduces the use of building materials, but also the use of skin effect in a small vibration shows better stiffness and improves the comfort when live in the wooden architecture. Because of wood environmentally friendly, wooden architecture has typical of the green ecological characteristics of wooden architecture increasingly welcomed by the people. The article will study the skin effect of bamboo waferboard wooden architecture. Analysis the models of the wall and wooden architecture which consider skin effect and do not consider the skin effect by using finite element software

The working principle of the skin effect is: the enclosure plate and purline and board and board are connected by different fasteners, forming a series of partitions with purline as its rib. This board has quite a large stiffness in the plane, is similar to the web, a thin-walled deep beam purlin is similar to the stiffener thin-walled deep beam, plate connection around the wall beam or purlin is similar to the flange of a thin-walled deep beam, which can be used to transfer plate plane shear, all sorts of plate under in-plane loading. The skin structure is mainly composed of the skin plate, frame structure and fittings.

\section{the structure of the monskin plate}

Wood structure of pedal mainly USES plywood, plywood is by the logs by wood square plane rotary cut veneer or cut it into two sub-companies named seaport, reoccupy adhesive agglutination of three layer or layers of plate material, usually with an odd number of veneer, and make the fiber direction perpendicular agglutination adjacent veneer. A set of veneer usually is formed by the vertical forming of the blank in the direction of the adjacent layer of wood grain. Usually the plate and the inner plate are configured on both sides of the center or the core of the board. The plate is crisscrossed with wood grain in the direction of wood grain, and it is compressed by heating or not heating. The number of layers is usually odd, and the few have even Numbers. The physical and mechanical properties of the transverse direction are small. Commonly used plywood type has 3 plywood, 5 plywood and so on. Plywood can improve wood utilization and is a main way to save wood. The following are some common plywood, as shown in figure 1 , figure 2 , figure 3 , as shown 
in figure 4.

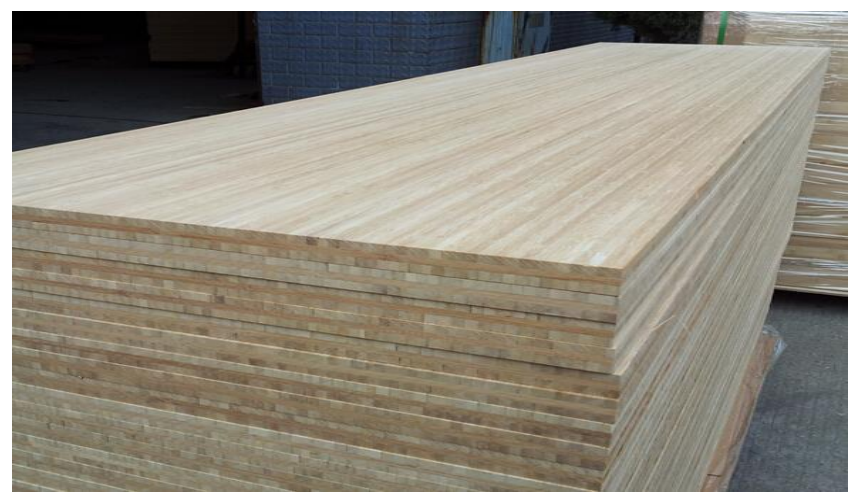

Fig.1 Bamboo plywood

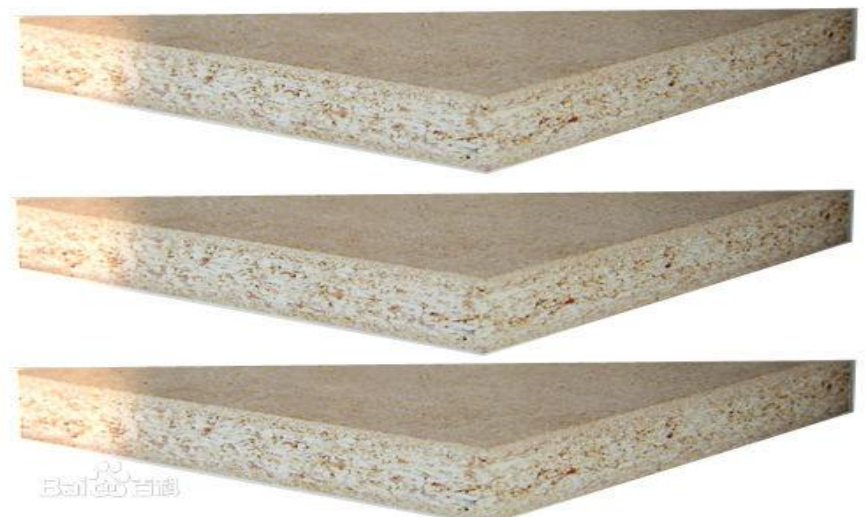

Fig.2 Particle board

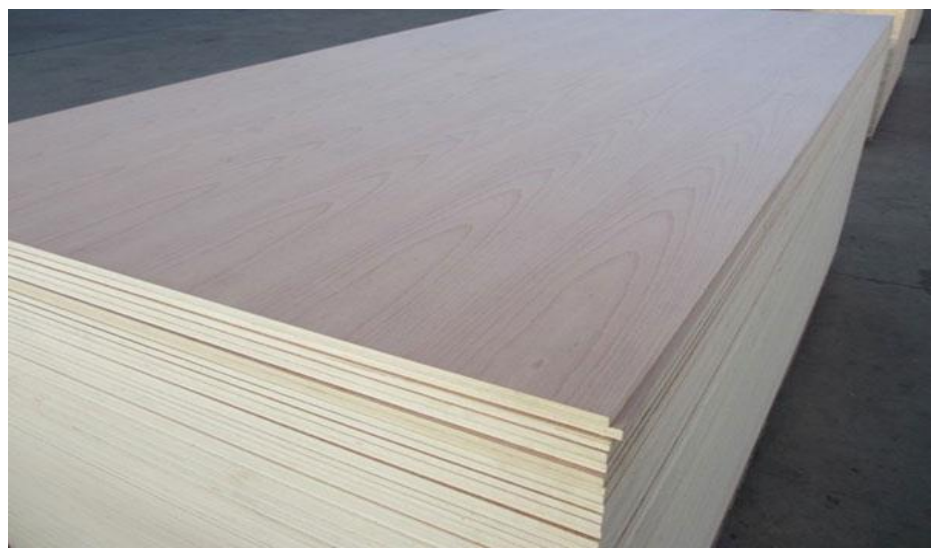

Fig.3 $9 \mathrm{~mm}$ plate 


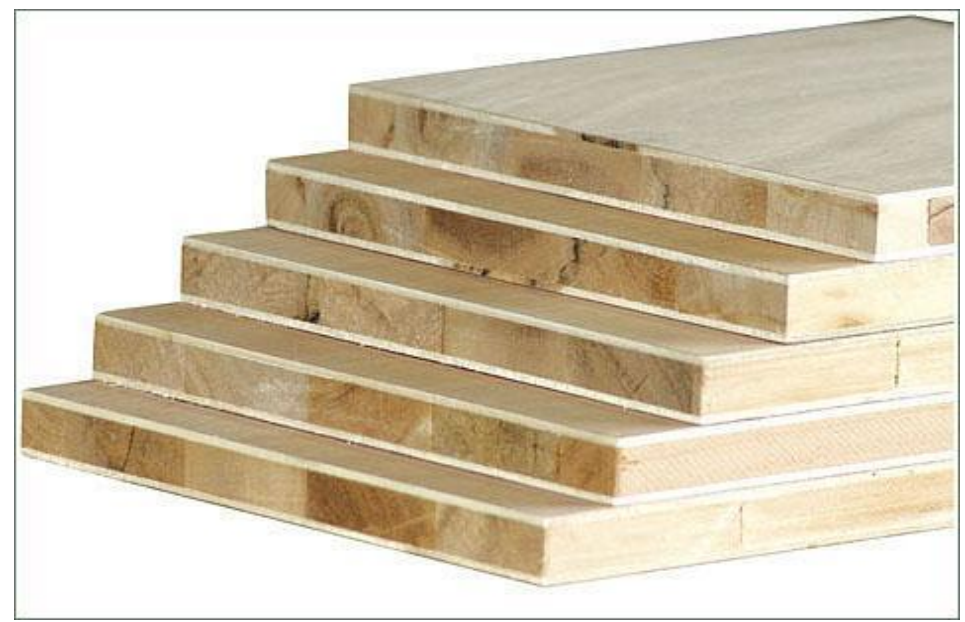

Fig.4 Core-board

\section{layout type of montpelle}

The mask can be considered as a beam with a high section height, which is the size of the direction of parallel to the load, and its span is the dimension perpendicular to the direction of load. In the direction of the load envelope body by plane direction of the relationship between span of skin, the skin body can be divided into the board across the direction parallel to the skin span across the skin body board in vertical direction of skin body skin span two types. Two types of montmorillus can be fixed to the supporting structure in two ways. When the skin plate is fixed on the vertical component and is fixed on the parallel component, the four sides of the mask are directly connected with the supporting member (known as direct shear transfer). When the mask is only fixed with the vertical structure of the supporting structure, the cover is only connected with the supporting structure on both sides (known as the indirect shear transmission).

\section{Acknowledgements}

This work was financially supported by Yunnan Provincial Key Laboratory of Wood Adhesives and Glued Fund Products;Yunnan Science and Technology Department Fund Project(2016RA079); Yunnan Provincial Department of Education Fund Project (2015Y298) . The corresponding author is GUO Zhongli.

\section{Reference}

[1] Nilson A H \& Ammar A R . Finite Element Analysis of Metal Deck Shear Diaphragms. Proceeding of ASCE. Structure Division April, 1974.

[2] Davies, J.M., Lawson, R.M.. The Shear Flexibility of Profiled Sheeting [A]. 3rd Conference on Cold-Formed Steel Structures[C]. University of Missouri-Rolla, Nov, 1975.

[3] ECCS. European Recommendation for the Stressed Skin Diaphragm Design of Steel Structure, 1997.

[4] Davies, J.M and Bryan. E.R.Manual of Stressed Skin Diaphragm. Granada, 1982.

[5] Gianfranco De Matteis and Raffaele Landolfo. Mechanical fasteners panels: Interpretative models for shear behaviour, Volume: 35, Issue: 1, September. 1999, 61-79. 